\title{
Bonding Durability between Orthodontic Brackets and Human Enamel treated with Megabond Self-etching Primer Using 4-META/MMA-TBB Resin Cement
}

\author{
Somsak SIRIRUNGROJYING, Tohru HAYAKAWA', Kayo SAITO ${ }^{2}$, Daijiro MEGURO², Kimiya NEMOTO ${ }^{1}$ \\ and Kazutaka KASAI ${ }^{2}$ \\ Department of Orthodontics, Nihon University Graduate School of Dentistry at Matsudo, 2-870-1, Sakaecho Nishi, Matsudo, \\ Chiba 271-8587, Japan \\ ${ }^{1}$ Department of Dental Materials, Research Institute of Oral Science, Nihon University School of Dentistry at Matsudo, 2- \\ 870-1, Sakaecho Nishi, Matsudo, Chiba 271-8587, Japan \\ ${ }^{2}$ Department of Orthodontics, Nihon University School of Dentistry at Matsudo, 2-870-1, Sakaecho Nishi, Matsudo, Chiba \\ 271-8587, Japan \\ Corresponding author, E-mail:somsak@mascat.nihon-u.ac.jp
}

Received March 9, 2004/Accepted April 28, 2004

\begin{abstract}
The purpose of this study was to determine the bonding durability when a Megabond self-etching primer is used with 4META/MMA-TBB resin to bond metal orthodontic brackets to human premolar enamel. Three conditions of enamel were prepared: Megabond self-etching primer without saliva contamination, Megabond self-etching primer with saliva contamination, and repeat Megabond self-etching priming after saliva contamination. Shear bond strengths were measured after immersion in water at $37^{\circ} \mathrm{C}$ for 24 hours, or after 2000 or 5000 cycles of thermal cycling between $5^{\circ} \mathrm{C}$ and $55^{\circ} \mathrm{C}$. There were no significant differences in shear bond strength among the three groups not only before thermal cycling, but also after thermal cycling. FE-SEM observation revealed the presence of saliva and reduced amount of resin tag formation after saliva contamination.
\end{abstract}

The present study provided the evidence in human teeth that when using 4-META/MMA-TBB resin, Megabond selfetching primer treatment produced tight bonding even when surface was contaminated with saliva.

Key words: Thermal cycling, 4-META/MMA-TBB resin, Saliva

\section{INTRODUCTION}

Currently, adhesive resin cements are widely used to bond orthodontic brackets to enamel. 4-META/ MMA-TBB resin cement is a unique MMA-based adhesive resin cement used widely for bonding orthodontic brackets and has earned a reputation for its strong bonding capability ${ }^{1-7)}$. Manufacturers recommend applying $65 \mathrm{wt} \%$ phosphoric acid etchant for 4-META/MMA-TBB resin to adhere tightly to enamel ${ }^{8)}$.

Self-etching primers that function both as etchant and primer have been used widely to substitute phosphoric acid etching in resin composite restorations. Apart from their efficacy in adhering to dentin and enamel, which has been favorably reported in various studies $^{9-11)}$, self-etching primers offer other advantages. It is not necessary to rinse the enamel after applying self-etching primer. By using a self-etching primer instead of phosphoric acid for the 4-META/MMA-TBB resin, both the procedural steps and time required to bond orthodontic brackets to teeth are reduced. Indeed, the time saved from using a self-etching primer is more than that spent in preparing the adhesive before bonding.

Moreover, phosphoric acid etching techniques have been claimed to cause iatrogenic damage to the enamel. Some in vitro studies observed enamel fracture after debonding the orthodontic bracket bonded to etched enamel. The amount of enamel fracture was found to be proportional to the length of etching time $\mathrm{e}^{12-15)}$. In some clinical studies where glass-ionomer cement was used as a comparison ${ }^{16,17)}$, composite resin adhesive with phosphoric acid etching produced a greater number of white spots on the enamel at debonding as well as more damage on the enamel.

In orthodontic treatments, especially those for binding attachments to impacted or lingual tooth surfaces, it is very difficult to completely prevent cleansed and dried enamel surfaces from being contaminated with blood and water. Various studies have reported reduced shear bond strength when resin is directly bonded to saliva-contaminated etched enamel ${ }^{18-20)}$. Itoh et $a l^{21)}$ reported that saliva and blood contamination decreased the bond strength of 4-META/MMA-TBB resin in orthodontic brackets bonded to the polished anterior surface of bovine teeth, which was etched with phosphoric acid. Arita et $a l^{22)}$ also reported that saliva contamination decreased the shear bond strength of orthodontic bracket with 4-META/MMA-TBB resin to etched bovine or human enamel.

Based on the above-mentioned results, we designed an experiment to confirm the efficacy of selfetching primer treatment and the effect of saliva 
contamination in bonding orthodontic brackets to human enamel using 4-META/MMA-TBB resin. In a previous study ${ }^{23)}$, we have demonstrated that selfetching primer was a better candidate than phosphoric acid etchant for preparing the enamel surface. This is because when used with 4-META/MMA-TBB resin to bond orthodontic bracket to enamel, selfetching primer produced a bond strength comparable to that by phosphoric acid etching. In addition, saliva contamination did not affect the bond strength, and there was no need for repeat treatment with self-etching primer after saliva contamination.

For successful and effective treatment of patients, it may be important to ensure that long-term durability of bracket bonding to enamel exists. To this end, the bonding durability of 4-META/MMATBB resin to enamel was assessed in various studies. Mogi et al. ${ }^{1)}$ reported that the tensile bond strength of 4-META/MMA-TBB resin cement used on bovine enamel etched with phosphoric acid decreased to almost 60 percent of the initial bond strength after one year's immersion in water at $37^{\circ} \mathrm{C}$. Miwa et $a l^{24)}$ found a decrease in tensile bond strength after 3000 and 10,000 thermal cycles when orthodontic bracket was bonded with 4-META/MMA-TBB resin to enamel etched with phosphoric acid. Hayakawa et al. ${ }^{25)}$ also reported a significant decrease in tensile bond strength after 5000 thermal cycles when 4META/MMA-TBB resin was used on bovine enamel etched with phosphoric acid. Saito et al. ${ }^{26)}$ found that self-etching treatment was superior to phosphoric acid as an enamel preparation agent. The former provided a significantly higher shear bond strength as determined by thermal cycling tests - when orthodontic bracket was bonded to hurnan enamel after phosphoric acid etching or self-etching primer treatment using 4-META/MMA-TBB resin. However, the influence of saliva contamination on bonding durability was still not clear.

The purpose of the present study was to assess - after thermal cycling tests when the teeth were contaminated with saliva - the shear bond strength of orthodontic bracket to human enamel. The enamel was treated with self-etching primer using 4-META/MMA-TBB resin. The surface appearance of human enamel and the amount of resin tag formation after saliva contamination were then observed using field-emission scanning electron microscope (FE-SEM).

\section{MATERIALS AND METHODS}

Extracted human premolars were used in this study, except those with cracks. The teeth were embedded in acrylic resin with the buccal surfaces available for bonding. After curing the acrylic resin, the tooth surfaces to be bonded were cleansed and then polished with pumice and rubber prophylactic cups for 10 seconds to simulate a routine clinical procedure.

\section{Shear bond strength measurement}

Table 1 lists the materials used in the present study. For the orthodontic bracket, orthodontic metal brackets (Super mesh STD Edgewise 131-45B, Tomy International Inc., Tokyo, Japan) were used. The average bracket surface area was determined to be $11.188 \mathrm{~mm}^{2}$. Megabond self-etching primer (Kuraray Medical Inc., Tokyo, Japan) was used as the selfetching primer because Hayakawa et $a l^{27)}$ demonstrated that Megabond self-etching primer gave the highest mean bond strength among several kinds of commercially available self-etching primer.

Fig. 1 shows the schematic drawing on how to measure shear bond strength between the orthodontic bracket and enamel with 4-META/MMA-TBB resin. Megabond self-etching primer was placed on the enamel for 20 seconds. Excessive primer solution was evaporated using compressed air. Primed enamel surfaces were then divided into three groups: Group 1 - Megabond self-etching primer without saliva contamination; Group 2 - Megabond self-etching primer with saliva contamination; and Group 3 Repeat Megabond self-etching priming after saliva contamination.

Table 1 Materials used in this study

\begin{tabular}{lclcl}
\hline \multicolumn{1}{c}{ Material } & Component & \multicolumn{1}{c}{ Composition } & Lot No. & Manufacturer \\
\hline $\begin{array}{l}\text { 4-META/MMA-TBB } \\
\text { resin }\end{array}$ & Etching agent & 65 wt\% phosphoric acid & $2005-02$ & $\begin{array}{l}\text { Sun Medical Co. Ltd., } \\
\text { Shiga, Japan }\end{array}$ \\
& Polymer powder & Polymethyl methacrylate & $2005-03$ & $2004-07$ \\
& Monomer liquid & 4-META, MMA & $2004-01$ & \\
& Catalyst & Partly oxidized TBB & 00103A & $\begin{array}{l}\text { Kuraray Medical Inc., } \\
\text { Tokyo, Japan }\end{array}$ \\
\hline $\begin{array}{l}\text { Megabond self-etching } \\
\text { primer }\end{array}$ & & $\begin{array}{l}\text { MDP, HEMA, polyfunctional } \\
\text { dimethacrylates }\end{array}$ & &
\end{tabular}

4-META indicates 4-methacryloloxyethyl trimellitate anhydride; MMA, methyl methacrylate; TBB, tri-n-butyl borane; MDP, 10-methacryloxydecyl dihydrogen phosphate; HEMA, 2-hydroxyethyl methacrylate 
Saliva contamination was performed as follows. The enamel treated with self-etching primer - in Group 2 - was contaminated with $20 \mu$ l of human fresh whole saliva. The contaminant fluids were left on the surface for 30 seconds to simulate extremely severe clinical conditions before the saliva was blown off using compressed air for 5 seconds. In Group 3, saliva-contaminated teeth were again treated with Megabond primer for 30 seconds, before using compressed air to blow off saliva from the enamel surface. The pretreatment procedures are summarized in Table 2.

The metal orthodontic bracket was bonded to each enamel surface using 4-META/MMA-TBB resin cement. The catalyst, a partly oxidized TBB initiator, was added to the monomer mixture of 4-META and MMA to prepare an activated polymerized monomer liquid. The polymer powder and activated monomer liquid were then mixed and applied to bond metal brackets to the treated enamel surfaces using the brush-dip technique. Each bracket was subjected to a $300-\mathrm{g}$ force, according to experimental setup in the report of Bishara et al. ${ }^{28)}$, and excess bonding resin was removed with a small scaler.

After bonding, the teeth were kept in deionized

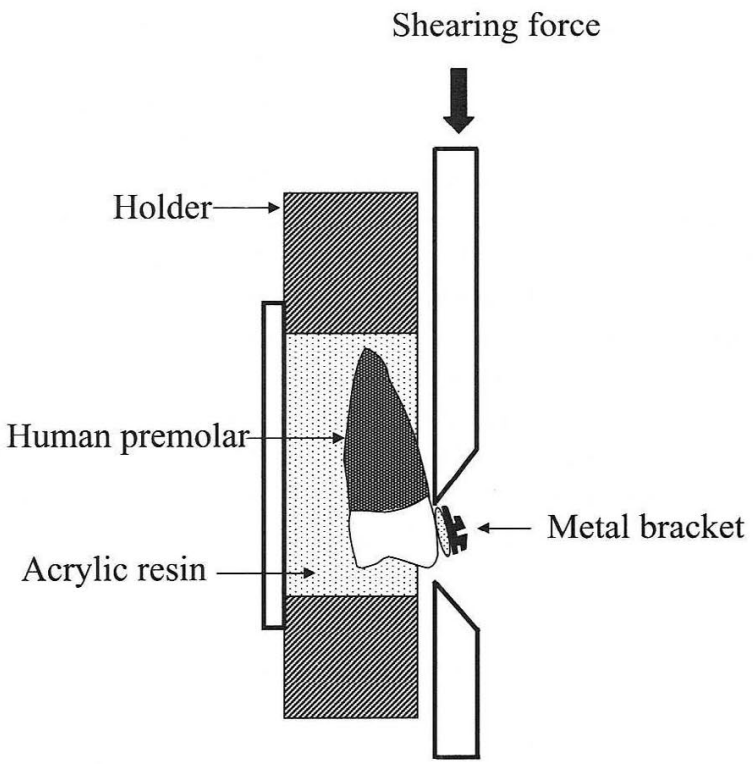

Fig. 1 Schematic illustration of the specimen for shear bond strength measurement. water at $37^{\circ} \mathrm{C}$ for 24 hours, subjected to thermal cycling test for 2000 or 5000 cycles, and then debonded. Thermal cycling was performed between $5^{\circ} \mathrm{C}$ and 55 ${ }^{\circ} \mathrm{C}^{29)}$. The specimens before thermal cycling tests provide baseline data for comparative purpose. The exposure in each bath was 60 seconds, and the transfer time between baths was less than 5 seconds.

Shear bond strength was measured using a testing machine (TCM-500CR, Shinkoh, Tokyo, Japan) at a cross-head speed of $2 \mathrm{~mm} / \mathrm{min}$, as done in previous reports ${ }^{4,23,26)}$. Twenty specimens were tested for each procedure. Two-way analysis of variance (ANOVA) and Fisher's test for multiple comparisons were used to detect statistical differences in mean measurements.

After debonding, the teeth and brackets were examined with $10 \times$ magnifications. The debonding condition of each specimen was scored using the adhesive remnant index (ARI ${ }^{30)}$. The ARI scores ranged from 0 to 3 , where score $0=$ no adhesive remained on the enamel; 1 = less than half of the adhesive remained on the tooth surface; 2 - more than half of the adhesive remained on the tooth; $3=$ all the adhesive remained on the tooth with a distinct impression of the bracket base. Enamel fracture was also scored according to the method of Schaneveldt et $a l^{31)}$. The chi-square $\left(\chi^{2}\right)$ test was used to analyze statistical differences in ARI scores and enamel fracture scores among the six protocols. Significance for all statistical tests was predetermined at $\mathrm{p}<0.05$.

\section{FEM-SEM observation}

Three types of human enamel surface, namely selfetching primer without saliva contamination, selfetching primer with saliva contamination, and repeat self-etching primer, were prepared as described above.

After each treatment, the specimen was dehydrated through a graded series of ethanol, dried in a critical drying apparatus, and ion-coated with platinum. After which, the surface appearance of human enamel was observed using a field-emission scanning electron microscope (FE-SEM, JSM-6340-F, JEOL, Tokyo, Japan).

To observe the resin tags, 4-META/MMA-TBB resin cement was applied on each enamel surface. After curing the resin, the specimen was immersed into $4 \mathrm{~mol} / \mathrm{L} \mathrm{HCl}$ for 4 days and then immersed in 10 wt $\% \mathrm{NaOCl}$ solution. The enamel part was com-

Table 2 Pretreatment procedures for bonding orthodontic brackets

\begin{tabular}{cll}
\hline Grouping & \multicolumn{1}{c}{ Enamel surface priming } & \multicolumn{1}{c}{ Procedure } \\
\hline Group 1 & Without saliva contamination & Megabond self-etching primer \\
Group 2 & Saliva contamination & Megabond self-etching primer $\rightarrow$ Saliva contamination \\
Group 3 & $\begin{array}{l}\text { Repeat self-etching primer after saliva } \\
\text { contamination }\end{array}$ & $\begin{array}{l}\text { Megabond self-etching primer } \rightarrow \text { Saliva contamination } \rightarrow \\
\text { Repeat Megabond self-etching primer }\end{array}$ \\
\hline
\end{tabular}


pletely dissolved, and the remaining bonded resin was rinsed with water and dried in a desiccator under the vacuum. The resin specimens were ion-coated with platinum, and the formation of resin tags observed using FE-SEM.

\section{RESULTS}

Fig. 2 shows the results of shear bond strength measurements $(\mathrm{MPa})$. Two-way ANOVA showed significant differences in bond strength among the various thermal cycles $(\mathrm{p}<0.05, \mathrm{~F}: 4.365)$. No significant differences in bond strength existed among the various types of enamel surface condition $(p>0.05, F$ : 1.323). Two-way interactions were not found for any number of thermal cycles or enamel surface condition type (i.e., without saliva contamination, saliva contamination, and repeat self-etching primer after saliva contamination) $(\mathrm{p}>0.05, \mathrm{~F}: 0.415)$.

Among the different enamel surface conditions,

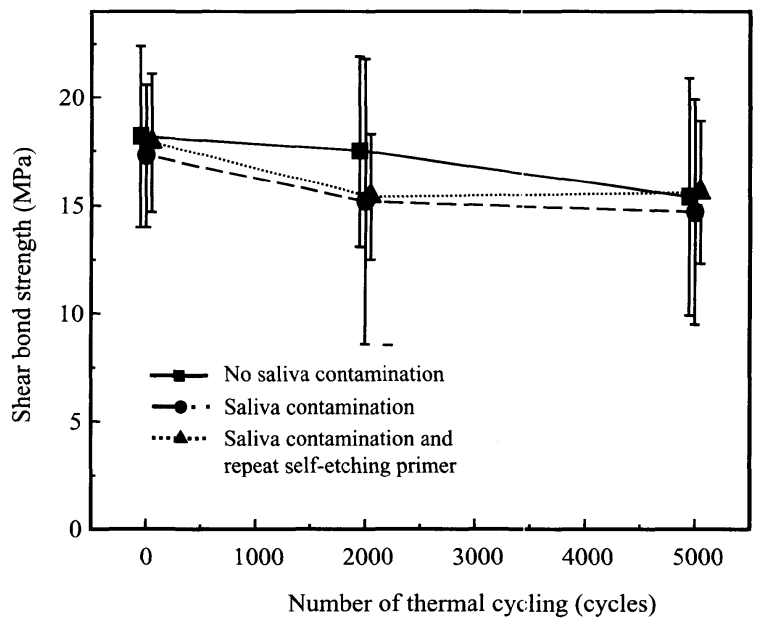

Fig. 2 Influence of thermal cycles or the shear bond strength between orthodontic brackets and human enamel. the following observations were noted. Before thermal cycling, shear bond strength of 17-18 $\mathrm{MPa}$ was obtained despite the difference in enamel surface conditions (i.e., without saliva contamination, saliva contamination, and repeat self-etching primer after saliva contamination). No significant differences in shear bond strength after 2000 and 5000 thermal cycles among the three enamel surface conditions. No significant decrease in bond strength after 2000 and 5000 thermal cycles for each enamel surface condition.

Table 3 shows the results of the frequency distribution of ARI scores and frequencies of enamel fracture after debonding. Chi-square test that included the ARI scores and enamel fracture showed significant difference in ARI scores among the three conditions $\left(\chi^{2}=40.177, \mathrm{p}<0.05\right)$. Complementary test showed a significant difference among the three groups before thermal cycling $\left(\chi^{2}=13.636, \mathrm{p}<0.05\right)$ and at 5000 thermal cycles $\left(\chi^{2}=8.277, \mathrm{p}<0.05\right) . \quad \mathrm{A}$ significant difference was also found between Group 2 (saliva contamination, $\chi^{2}=7.787, \quad \mathrm{p}<0.05$ ) and Group 3 (saliva contamination after repeat etching, $\left.\chi^{2}=10.750, \mathrm{p}<0.05\right)$, where enamel fracture frequency tended to decrease after saliva contamination.

Fig. 3 shows the FE-SEM micrographs of enamel surfaces. After self-etching priming treatment, there were no distinct dissolution patterns and the enamel surface appeared almost flat. No enamel crystals were observed. When the self-etch primed enamel was contaminated with saliva, the enamel surface was partially covered with saliva (arrow). Repeat self-etch priming after saliva contamination removed almost all the contaminated saliva on the enamel and produced more decalcification, compared with the original self-etch primed enamel surface.

Fig. 4 shows the resin tags formed on the selfetch primed enamel: On the enamel surface without saliva contamination, very short resin tags formed around the enamel peripheries (arrow) and no sharp

Table 3 Frequency distribution of the Adhesive Remnant Index (ARI)

\begin{tabular}{|c|c|c|c|c|c|c|}
\hline Number of thermal cycles & Procedure & $\mathrm{ARI}=0$ & $\mathrm{ARI}=1$ & $\mathrm{ARI}=2$ & $\mathrm{ARI}=3$ & $\mathrm{EF}$ \\
\hline \multirow[t]{3}{*}{0} & Without saliva contamination & 14 & 1 & 0 & 0 & 5 \\
\hline & Saliva contamination & 16 & 4 & 0 & 0 & 0 \\
\hline & $\begin{array}{l}\text { Repeat self-etching primer after } \\
\text { saliva contamination }\end{array}$ & 14 & 6 & 0 & 0 & 0 \\
\hline \multirow[t]{3}{*}{2000} & Without saliva contamination & 15 & 4 & 0 & 0 & 1 \\
\hline & Saliva contamination & 14 & 5 & 0 & 0 & 1 \\
\hline & $\begin{array}{l}\text { Repeat self-etching primer after } \\
\text { saliva contamination }\end{array}$ & 16 & 1 & 0 & 1 & 2 \\
\hline \multirow[t]{3}{*}{5000} & Without saliva contamination & 14 & 2 & 0 & 0 & 4 \\
\hline & Saliva contamination & 20 & 0 & 0 & 0 & 0 \\
\hline & $\begin{array}{l}\text { Repeat self-etching primer after } \\
\text { saliva contamination }\end{array}$ & 18 & 1 & 0 & 0 & 1 \\
\hline
\end{tabular}



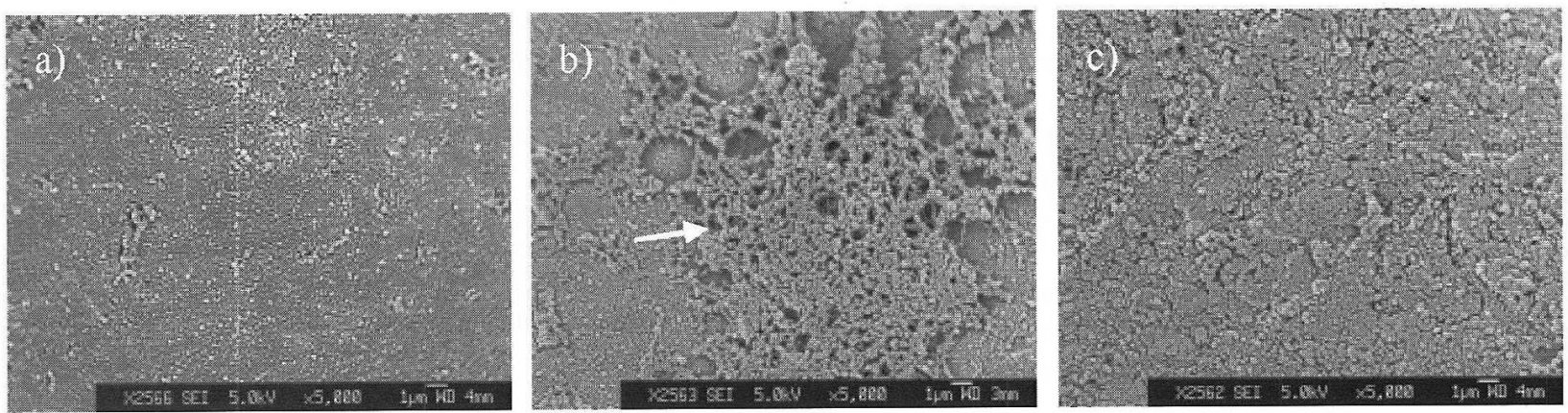

Fig. 3 FE-SEM views of enamel surfaces after self-etching primer treatment. (a): no saliva contamination, (b): saliva contamination, (c): saliva contamination and repeat self-etching primer.
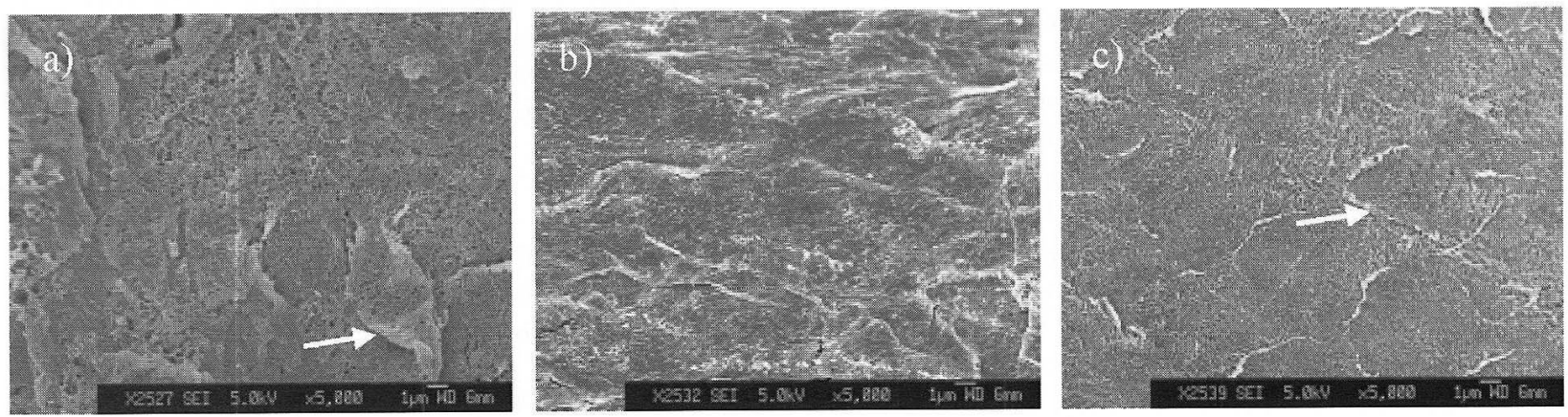

Fig. 4 FE-SEM images of resin tags formed on the self-etched primed enamel. (a): no saliva contamination, (b): saliva contamination, (c): saliva contamination and repeat self-etching primer.

resin tags were observed. After saliva contamination, the whole surface of resin tags appeared more smooth. After repeat self-etch priming, regular formation of resin tags was seen more clearly (arrow), compared with after saliva contamination.

\section{DISCUSSION}

To evaluate the bond strength of dental adhesive materials to teeth, bovine teeth were sometimes used to substitute human teeth ${ }^{32-34)}$. In the present study, we evaluated the bonding durability of orthodontic brackets to self-etching primed human enamel using 4-META/MMA-TBB resin. We also examined the influence of saliva contamination on human enamel.

Saito et $a l^{26)}$ previously reported that when orthodontic bracket was bonded to human enamel using 4-META/MMA-TBB resin and without saliva contamination, self-etching primer treatment produced more durable bond strength than phosphoric acid etching. The present study, however, revealed that self-etching primer treatment produced durable bond strength even though enamel was contaminated with saliva. In a clinical situation, it is more important to obtain adequate bond strength for bonding the orthodontic bracket to enamel during orthodontic treatment - and thereafter for safe and easy debonding - than to attain the greatest possible bond strength. In the present study, the enamel surface was examined under a dissecting microscope and the amount of adhesive remaining on the tooth recorded using ARI scores after debonding ${ }^{30)}$.

ARI scores are used to define the site of bond failure between the enamel, the adhesive, and the bracket base. Failure patterns in the present study were scored according to the method of Schaneveldt et $a l^{31)}$, which includes enamel fractures. In the present study, enamel fractures were observed in all the six thermal cycling tests, even after 5000 thermal cycles as shown in Table 3. Moreover, enamel fracture was observed regardless of enamel surface condition, although with saliva contamination less enamel fractures occurred during orthodontic bracket bonding.

Besides shear bond strength, we investigated two other factors: the influence of saliva contamination and resin tag formation. After saliva contamination, self-etch primed enamel surface was covered with saliva, and repeat self-etch priming almost completely removed the saliva contaminant.

It is generally recognized that the mechanical interlocking of cured resin (that is formed on a roughened enamel surface ${ }^{35,36)}$ ) contributes to the bond strength of dental resin materials to enamel. In the present study, resin tag formation was observed as follows: Very short resin tags were observed on the enamel without saliva contamination. Repeat selfetching after saliva contamination provided clear formation of resin tags due to removal of saliva 
contaminant. On the contrary, no clear resin tags were found on the saliva-contaminated enamel.

Two types of resin tag, macro- and micro-resin tags, contribute to the bond strength of dental resin to enamel. In the present study, there were no significant differences in shear bond strength among the three surface conditions - both before and after thermal cycling. Therefore, it is presumed that the formation of micro-resin tags resulted in the high shear bond strength of orthodontic bracket to enamel.

Moreover, Megabond self-etching primer contains methacryloyloxydecyl dihydrogen phosphate (MDP) ${ }^{37)}$. MDP is a well-known adhesive monomer, and is used as a component not only for self-etching primer but also for dental bonding agent. It is suggested that MDP or some interaction between MDP and calcium atom in hydroxyapatite improves the wettability of 4-META/MMA-TBB resin. The improved wettability then contributes to the high shear bond strength of orthodontic bracket to human enamel.

The excellent penetration ability of 4-META/ MMA-TBB resin is also another factor for the high shear bond strength obtained in the present study. The monomers of 4-META/MMA-TBB resin can penetrate through saliva and bond tightly to the saliva-contaminated enamel with the aid of MDP. Studies of the interface, for example FE-SEM observation of the interface between 4-META/MMA-TBB resin and saliva-contaminated enamel, would definitely help to elucidate this interfacial bonding.

In conclusion, the present study provided the evidence in human teeth that when using 4-META/ MMA-TBB resin as an orthodontic direct bonding adhesive, Megabond self-etching primer treatment produced the high shear bond strength of more than $15 \mathrm{MPa}$. This high value was obtained even though the enamel surfaces were contaminated with saliva and the tooth specimens subjected to thermal cycling. Based on the investigation results, Megabond selfetching primer treatment is proposed to be a clinically promising technique for bonding orthodontic bracket to human enamel using 4-META/MMA-TBB resin.

\section{ACKNOWLEDGEMENTS}

A part of this study was supported by a grant from the Ministry of Education, Culture, Sports, Science and Technology to promote the 2001-Multidisciplinary Research Projects (in 2001-2005).

\section{REFERENCES}

1) Mogi M. Study on the application of 4-META/MMATBB resin to orthodontics. I. Adhesion to human enamel. J Jpn Orthod Soc 1982; 41: 260-271.

2) Nakabayashi N. Adhesive bonding with 4-META. Oper
Dent 1992; suppl 5: 125-130.

3) Zachrisson BU, Buyukyilmaz T, Zachrisson YØ. Improving orthodontic bonding to silver amalgam. Angle Orthod 1995; 65: 35-42.

4) Kawasaki M, Hayakawa $T$, Takizawa T, Sirirungrojying S, Saito K, Kasai K. Assessing the performance of a methyl methacrylate-based resin cement with self-etching primer for bonding orthodontic brackets. Angle Orthod 2003; 73: 702-709.

5) Hirabayashi C, Imai Y. Studies on MMA-TBB resin. I. Comparison of TBB and other initiators in the polymerization of PMMA/MMA resin. Dent Mater J 2002; 21: 314-321.

6) Kameyama A, Ihara S, Amagai T, Miake Y, Kawada E, Oda Y. Adhesion of 4-META/MMA-TBB resin to heated dentin: Effects of pre-treatment with $\mathrm{FeCl}_{3}$ and/or HEMA. Dent Mater J 2003; 22: 1-9.

7) Hirabayashi C. Studies on MMA-TBB resin. II. The effect of dual use of TBB and other initiators on polymerization of PMMA/MMA resin. Dent Mater J 2003; 23: $48-55$.

8) Nakagawa K. Studies on the direct bonding of the orthodontic resin bracket to the tooth enamel: Part 2 The effect of pretreatment on the enamel surface. $\mathrm{J}$ Jpn Orthod Soc 1969; 28: 278-285.

9) Barkmeier WW, Los SA, Triolo PT Jr. Bond strengths and SEM evaluation of Clearfil Liner Bond 2. Am J Dent 1995; 8: 289-293.

10) Gordan VV, Vargas MA, Cobb DS, Denehy GE. Evaluation of acidic primers in microleakage of Class 5 composite resin restorations. Oper Dent 1998; 23: 244-249.

11) Hayakawa $T$, Kikutake $K$, Nemoto $K$. Influence of selfetching primer treatment on the adhesion of resin composite to polished dentin and enamel. Dent Mater 1998; 14: 99-105.

12) Wang WN, Lu TZ. Bond strength with various etching times on young permanent teeth. Am J Orthod Dentofacial Orthop 1991; 100: 72-79.

13) Sheen DH, Wang WN, Tarng TH. Bond strength of younger and older permanent teeth with various etching times. Angle Orthod 1993; 63: 225-230.

14) Stratmann U, Schaarschmide K, Wegener H, Ehmer U. The extent of enamel surface fractures. A quantitative comparison of thermally debonded ceramic and mechanically debonded metal brackets by energy dispersive micro- and image-analysis. Eur J Orthod 1996; 18: 655-662.

15) Toledano $M$, Osorio $R$, Osaorio $E$, Romeo $A$, de la Higuera B, Garcia-Godoy F. Bond strength of orthodontic brackets using different light and self-curing cements. Angle Orthod 2003; 73: 56-63.

16) Marcusson A, Norevall LI, Persson M. White spot reduction using glass ionomer cement for bonding in orthodontics: a longitudinal and comparative study. Eur J Orthod 1997; 19: 233-242.

17) Hegarty DJ, Macfarlane TV. In vitro bracket retention comparison of a resin-modified glass ionomer cement and a resin-based bracket adhesive system after a year. Am J Orthod Dentofacial Orthop 2002; 121: 496- 
501.

18) Yamamoto T. The effect of contamination on the adhesion of composite resin to etched enamel. Jpn $J$ Conserv Dent 1981; 24: 93-114.

19) Xie J, Powers JM, McGunkin RS. In vitro shear bond strength of adhesive to normal and fluoridated enamel under various contaminated conditions. Dent Mater 1993; 9: 295-299.

20) Benderli Y, Gokee K, Buyukgokeesu S. In vitro shear bond strength of adhesive to normal and fluoridated enamel under various contaminated conditions. Quintessence Int 1993; 30: 570-575.

21) Itoh $T$, Fukushima $T$, Inoue $Y$, Arita $S$, Miyazaki K. Effect of water, saliva and blood contamination on bonding of metal brackets with a 4-META/MMA-TBB resin to etched enamel. Am J Dent 1999; 12: 299-304.

22) Arita S, Fukushima $\mathrm{T}$, Miyazaki $\mathrm{K}$, Itoh $\mathrm{T}$, Matsumotyo M. Influence of various contaminants on bonding of an orthodontic 4-META/MMA-TBB resin to etched enamel. Adhes Dent 2000; 18: 30-42.

23) Sirirungrojying S, Saito K, Hayakawa T, Kasai K. Efficacy of using self-etching primer with a 4-META/ MMA-TBB resin cement in bonding orthodontic brackets to human enamel and effect of saliva contamination on shear bond strength. Angle Orthod 2004; 74: 251-258.

24) Miwa H, Miyazawa K, Goto S, Kondo T, Hasegawa A. A resin veneer for enamel protection during orthodontic treatment. Eur J Orthod 2001; 23: 759-767.

25) Hayakawa $T$, Nemoto K. Efficacy of self-etching primers in the adhesion of 4-META/MMA-TBB resin cement to enamel. J Adhes Dent 2002; 4: 105-113.

26) Saito K, Sirirungrojying S, Meguro D, Hayakawa T, Kazai T. Bonding durability of using self-etching primer with 4-META/MMA-TBB resin cement to bond orthodontic brackets. Angle Orthod in press.

27) Hayakawa $T$, Kikutake K, Kimiya N. Application of self-etching primer on 4-META/MMA-TBB resin -Effect on the adhesion to enamel. Adhes Dent 2001; 19: 38-47.

28) Bishara SE, Ajlouni R, Laffoon JF, Warren JJ. Effect of a fluoride-releasing self-etch acidic primer on the shear bond strength of orthodontic brackets. Angle Orthod 2002; 72: 199-202.

29) ISO TRE 11405. Dental materials - Guidance on testing of adhesion to tooth structure. 1994; pp.1-14.

30) Årtun J, Bergland S. Clinical trials with crystal growth conditioning as an alternative to acid-etch enamel pretreatment. Am J Orthod 1984; 85: 333-340.

31) Schaneveldt S, Foley TF. Bond strength comparison of moisture insensitive primers. Am J Orthod Dentofacial Orthop 2002; 122: 267-273.

32) Watanabe K, Ohnishi E, Kaneshima T, Mine A, Yatani $\mathrm{H}$. Porcelain veneer bonding to enamel with plasma-arc light resin curing. Dent Mater J 2002; 21: 61-68.

33) Liu J, Hattori M, Hasewgawa K, Yoshinari M, Kawada E, Oda Y. Effect of tubule orientation and dentin location on the microtensile strength of bovine root dentin. Dent Mater J 2002; 21: 73-82.

34) Hamano N, Hanaoka K, Ebihara K, Toyoda M, Teranaka T. Evaluation of adhesive defects using an ultrasonic pulse-reflection technique. Dent Mater $J$ 2003; 22: 66-79.

35) Retief DH. The mechanical bond. Int Dent J 1978; 28 : 18-27.

36) Retief DH. Clinical applications of enamel adhesive. Operative Dent 1992; suppl 5: 44-49.

37) Fujisawa S, Kadoma Y, Komoda Y. HPLC separation of methacryloyloxy dihydrogen phosphate from dental bonding agents. J J Dent Mat 1991; 10: 30-34. 